\title{
Ideology in Translating News Headline: A Critical Discourse Analysis Point of View
}

\author{
Eka Yunita Liambo \\ Applied Linguistic Program \\ Yogyakarta State University \\ Yogyakarta, Indonesia \\ ekaliambo@gmail.com
}

\author{
Sulis Triyono \\ Applied Linguistic Program \\ Yogyakarta State University \\ Yogyakarta, Indonesia \\ sulis@uny.ac.id
}

\begin{abstract}
Translation study is no longer seen as the product where the analysis stays on the strategy and method. Further, the process can be analyzed through both the source text and the target text. What can be seen here is the factors influences the translator in translating or reproducing the text. Translation study has found its close relationship with Critical Discourse Analysis (CDA). There are many studies conducted by previous researcher who have successfully liked translation study and CDA. Therefore this research also tries to prove the link between translation study and CDA. Its focus is to determine the translator's ideology in translating news headlines. The researcher randomly took 20 news headlines from $B 2 B$, a news website, in order to get the authentic data. The news headlines taken as the data are translated by one translator. This analysis is based on the first model of method proposed by Al-Hejin adopted from Norman Fairclough. The finding shows that the translator transmitted her ideology and view point into the translated news headlines. It was indicated from the analysis of textual dimension which includes diction, grammatical form, thematization, as well as addition and omission. From the result found, the translator tried to attract the readers by 'extreme' diction and grammatical form as well as omission and addition.
\end{abstract}

Keywords-Critical Discourse Analysis; ideology; news headline; Norman Fairclough; translation

\section{INTRODUCTION}

Translation is no longer seen only as a representation of a text. Translation is seen as having a hidden role to convey someone's ideology. Perceiving the meaning of a text is influenced by social cognition and a translator's perspective on the world. This can have an impact on the choice of vocabularies and constructing it in the target language. Thus it can be said that the translator may indirectly represent his ideology or thought through his work.

Since the analysis of translation studies only focuses on the product of translation, there are few studies concerning the process of translation. In so far, previous research has focused more on translation results concerning on translation studies such as strategy, methods, equivalents and etc. Unfortunately, the factors that influence the outcomes or things that occur in the translation process involving social factors are not much ogled by previous researchers. Only in the recent time, the review of translations associated with Critical Discourse Analysis (CDA) has become a born-trend in the science of translation and discourse analysis.

Therefore, this study aims to uncover the translator's ideology in translating the news headline that led to a shift in the focus of information. This type of study seems to be new because there are only several research studying the translation of news by using CDA framework. However, those studies do not focus on the news headline. Hence, this study can also fill the gap between translation studies and CDA. Furthermore, this study is expected to help in expanding the development of subsequent better translation analysis in relation to the process and in particular the CDA and it is able to benefit in terms of translation of news headline in any media.

\section{THEORETICAL REVIEW}

\section{A. Translation Study and Critical Discourse Analysis}

The study of critical discourse analysis and translation study has long been seen to have a relationship. The theories used by some translation experts largely take Halliday's framework as a reference in their arguments. One of them is seen from House using the mode, theme/rhyme, and tenor in her application for quality assessment of translation [1]. House is inspired by Halliday's theory which then divides the details of translation quality assessment into registers, genres, tenors, modes and field to become a reference in translation quality assessment [2, p. 65]. This indicates the relationship between translation and critical discourse analysis can be said very close. Not only that, some research has been conducted by using framework of critical discourse analysis and translation study.

The research using framework of CDA and translation study was conducted by Sami S. Alghamdi [3]. He studied the ideology based on the CDA framework that aims to see the relationship between ideology and language involved in the translation text. His study also aims to see whether the cultural and social factors as well as the ideology of the translator affect the production of translated texts. The subject of his research was Noam Chomsky's book entitled "Media Control” which is translated into Arabic language in two version. The results 
show that there were high differences of the diction of two version of the target texts. The syntactic structures are also different from the source language. This indicated that there was a transmission of ideology through the process of translation resulting the two version of TT.

The next study is comes from by Mahdi Aslani and Bahloul Sahlani [4]. Their research aims to uncover the role of ideology in translation process. The result of the study found that there was ideological stand points influenced the process of translation news in media. The ideology came from patron of the media. It was concluded that translated news were biased.

The research conducted by Mahdiyan in 2013 [5] also tried to analyze translation by using CDA framework. They uncovered the relationship language and ideology in translation by analyzing translated political speeches and interviews of Bush in 2005 till 2008. The research found that the implication of CDA in translation made translator more aware of social and situational context of source text and target text. It also helped them to reveal the ideology hiding in the translated text.

The above studies use the CDA model of Fairclough. Actually, there are many more studies that try to reveal the relationship between CDA and translation study. One research that is eager to prove the relationship between CDA and translation study is a research written by Bandar Al-Hejin [6] entitled Linking critical discourse analysis with translation studies in 2012. In his writing he tries to draw the midline of the relationship between CDA and translation study. In fact he proposes three CDA-Translation Study models that can be used to analyze translation in perspective of CDA. The model proposed by [6] is also based on Norman Fairclough's framework and then he links with translation theory of recontextualisation analysis. This model will be discussed in detail in the subsection below.

\section{B. Translation News}

News is a part of media. In today's life, media is a big bridge of a mass communication. Media can even change the way societies communicate [4]. It can even change the way people think. Media in the development of technology may lead to the influence of news immediately. Hence, the translation of news is needed in the spreading of information.

\section{1) The influence of target language culture}

Kang (in [3]) suggests that in the process of translating text into another language there is an influence of target language culture and norms to the translators that will be a big consideration. By this, the translator is not intended to reformulate a text by his willing by ignoring the interest of the target reader in another language. Interest here deals with the norms and socio-cultural context of the target language in order that the reformulated text can be understood and accepted without any efforts done.

\section{2) The transmission of ideology through translation}

Translation is not only seen as transferring message from one language to another language. Further, it is rewriting of an original text which hides translators' ideology (Lefevere in
[4]). This suggests that in rewriting the original text, a translator uses his experience or opinion to see the meaning of the original text then write it in another language. This is in line with Schäffner (in [7]) saying that all translational products are ideological as the way the translators intend the reformulation text is based on their social perspective and interest and it can be analyzed in grammatical aspects and lexical.

\section{The Three Methodological Models of Hejin}

This three methodological models are resumed from the studies conducted by several researchers about critical discourse analysis and translation adapted from Norman Fairclough's models of CDA. This models try to link the relation between CDA and Ts. Hejin [6] proposes three models of method which can be used to analyze the translation in CDA perspective. This models can also be used in different cases based on the model proposed.

The first model of method is agreeable to use to analyze when the translation is underlined as rewriting. In this model, both the author and the translator are seen the same where they can affect the text with their ideology and perspective. Hence, this model analyze the discursive and sociocultural practice of the translators determining in the target language domain. The image of model one is below:

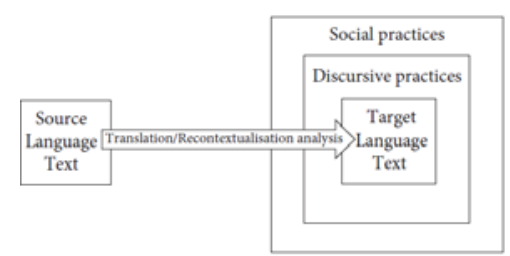

Fig. 1. The First Model of Three Methodological Model of Hejin adapted from Fairclough

The second model sees the translation as intertextual chain which conducts the comparative study of CDA of a text, discursive and social practice of SL and TL. This model is appropriate for those who want to know further what motivation behind lexical items chosen by the translator. This model is usually used to analyze the political speeches or biographies.

The last model of Hejin's methods regards the translation as the multiple version of a text. This model is used when there are two or more version of translated text. It is a comparative study of CDA of two or more target text along with the source text.

From the three models of methodology, the researcher decides to use the first model of Hejin's methods since the target text of the data is only one and it does not focus on the intertextual text. As the first method suggests, the researcher will analyze the discursive and sociocultural practice of the translators determining in the target language domain.

\section{MethodolOgy}

This research is descriptive-qualitative method. Analysis model in this study is constructed by referring to the CD-TS model by Al-Hejin (2008) adopting Fairclough theory of CDA. 
This study aims to uncover the ideology in translating news headline in B2B, a news website. This website writes news about Indonesia and world which is then translated into English. It has six news sectors in 'news bar' which are law, economics, politics, social, education, and advertorial. The researcher then decided to take randomly 20 news headline only translated by Novita Cahyadi. Therefore, the total of the data in present study is 20 news headline. The data then was analyzed by comparing the source text and target text by looking at only dimension of the text including lexicalization along with grammatical aspects (passive and active) thematization, addition, and omission.

\section{FINDING AND DISCUSSION}

From the analysis done by the researcher, it was found that there was something the translator wants to achieve by choosing a particular diction, changing the grammatical structure, doing omission and addition. At a glance, the distinction between Indonesian news headline, as source text, and English news headline, as target text, is visible. The differences lie in the aspects to be discussed further below:

\section{A. Lexicalization}

In this aspect, the emphasis is the selection of words/diction. The translator must have a certain purpose in choosing words to express the meaning in the target language. In this case, the diction used by the translator in translating the news headline is the vocabularies classified as 'extreme', 'cruel', as well as 'conspicuous'. Below are the example of the diction used by the translator:

\section{ST: WiFi Gratis Pemkot Solo Disalahgunakan Disorot Media Asing}

\section{TT: Indonesian City to Citizens: Stop Using Free WiFi for} Drugs and Prostitution

From the two examples above, it can be seen that the original authors does not choose the extreme and cruel diction in ST. In contrary to the ST, such diction is dominantly used even seems intentionally to be used. In the first TT there are the word stop, drugs, and prostitution.

Seen lexically, the original author of Indonesian discourse (T1) still refers to the Indonesian culture. It is proved by the word 'disalahgunakan' in which this word belongs to the general word. Hence, the ideology of the original author belongs to Indonesian culture by following the norm of Indonesian. In different side, the translator or the author of second discourse uses 'drugs and prostitution'. These words are still taboo in Indonesia because these words sound extreme. It indicates that the translator imposes her ideology by replacing the word 'disalahgunakan' in first discourse into 'drugs and prostitution' in second discourse. Looking at this fact through the social lens of discourse analysis, the translator tries to enter and adjust the culture of second discourse (T2). This this corresponds to Fairclough's sociocultural practice dimension that culture is one of considerations of producing a text. In this case, the translator's thought has been adjusted to the culture of where the text would be delivered.
Furthermore, seen generally the extreme and so called taboo words are dominantly used for particular purposes. The ideology of the translator is to attract the readers' attention especially from outside Indonesia. Thus, it can be summarized all the words that appears in 20 translation headlines by the translator are delayed, woes, knelling, prostitution, drugs, stop, brutally, masked, scambled, fight, outbreak, killed, scandal, death, boost, worried, secure, dead, strong, burn, shoot, radicals, attack, murdered, and protest.

These words when read at a glance can attract more attention and curiosity about what information actually in the news is. This kind of diction assumedly has a fixed pattern. There will be such diction in every news headline in TT. It means that most of the translation of news headlines in this research is strived to bring diction that is able to affect the readers to click the news. Actually, some of the extreme words above are not found or do not correspond to the first discourse (T1). This fact has a subjective reason. Since the translator works under the media power, her ideology has been affected by the demands of the media where the news should be attractive no matter how.

\section{B. Grammatical form (active and passive voice)}

In English, the use of active and passive voice is to determine or to emphasize something. The use of active form is generally used to show the actors doing the action. Whereas passive form is used to omit the information of an event. It can also be used to delete the actors who are not surely known. In this case, the translation of news headline involves the changing of the voice.

\section{1) Active to passive}

From 20 news headline translated by one translator, the changing of active to passive voice or vice versa was found eight (8) cases. There are 4 cases belonging to the changing from active to passive form. Here is one of the cases:

\section{ST: Berzinah, 10 Terhukum Jalani Hukum Cambuk di Aceh}

TT: Kneeling Woman is Brutally Caned for Adultery by Masked Sharia Law Enforcer in Indonesia

In this case, Indonesian discourse (ST) uses active form in which punished women is placed in the position of sentence subject. This indicate that the original author thinks that the offender deserves to be punished because of their mistake. The word "berzinah" is put in the beginning of the sentence in order to emphasize that their mistake is fatal since Aceh runs the law of Islam sharia. Also, the form of active in ST indeed sounds very common for the readers of Indonesia since there is no certain emphasis on this form.

In contrast, a strong emphasis is seen from the second discourse (TT) in which the punished women is also put in the position of sentence subject. Yet, the TT uses passive voice which indicates that the punished women are tortured when they are the offender. By changing the form from active to passive, the impression of the sentence changes as well. The form of passive of second discourse places the ten woman into the victim being persecuted when in reality they deserve to get the punishment. This of course raises the assumption that the 
translator has other ideology by deliberately changing the active form for a particular emphasis. In this case, the translator wants to follow the culture in which the second discourse appears by referring that free sex or having sex in west culture is a common case while in Indonesia especially Aceh, that kind of habit is very taboo. Therefore, the translator changes the form to show the oddity of Indonesian law for non-native of Indonesian. Seen from the media lens, this kind of form is more interesting for readers because the readers often put empathy to the victims which is usually placed in the beginning of passive sentence. Hence, the empathy will lead the readers to read the whole news.

\section{2) Passive to active}

In addition to changing the form from active to passive, the translation of news headlines also involves changing the form from passive to active. Similarly, active to passive changes, the changes from passive to active are found in four cases. Here is among them:

ST: Difteri Ditetapkan KLB, Kemenkes Gelar Program Imunisasi Pekan Depan

TT: Indonesia Fights `Extraordinary`Diphtheria Outbreak that has Killed 32

The case above shows that ST uses passive form and TT uses active form. The ST sounds positive that there is no a big problem in this form. Whereas the translated form or TT is seen negative since the form has been changed. The translated discourse or TT has been impacted by the translator ideology because the perspectives of both discourse are different. The perspective of ST has been shifted from positive to negative. The active form which sounds negative makes a big problem. This kind of form indicates that Indonesia has a serious problem since the word 'fights' which is considered as a serious action. This, of course, has ideological impact. In this view, the ideology of the translator is desiring to expose the action of the event. In this case Indonesian as the actors seem to be made brutal so that the readers want to find more information.

In sum, the changing of active to passive form or vice versa indicates that the two authors (original author and the translator) have different view point and ideology. Of course, this different view point also affects how someone conveys meaning in his own way. The translated discourse (TT) has been fully affected by the translator's ideology since the perspective of the text has been shifted.

\section{Thematization}

The second aspect in this analysis is thematization. The way author and translator order the information to purse the main information could be different as the result of different ideology. This aspect is intended to reveal the theme or main topic of text as well as the ideology affected the topic pointed. In this case the thematization is the focus of news headlines. Based on the analysis, the focus of theme in news headline translation was found shifted. Look at the data below:

ST: Vaksin Palsu Ancam Anak Indonesia Jadi Sorotan Media Asing

\section{TT: Parents Told to Contact Doctors Amid Indonesia Vaccine Scandal}

The case above shows that the topic is shifted. As seen in $\mathrm{ST}$, the original author emphasizes the focus of problem or the main topic is about the fake vaccine which threatens Indonesian kids. This topic is obviously about the phenomena where fake vaccine becomes the world attention. The ideology of the original translator lead the reader to the shocking effect. This further that Indonesia has been a focus of the entire world because of the vaccine case.

However, as seen in TT, the ideology of the translator is different from original author (ST). In TT the focus of problem is changed by the translator. The main topic is still about the fake vaccine. But, then it further more focus to the advice to Indonesian parents. 'Indonesian parent' is presented to give another effect of seriousness. The changing of theme of this case leads to different interpretation of readers. This indicates that the translator wants to give different effect for the readers. The topic of TT is more serious since it involves parents and advice to call the doctor in order that the parents can discuss about their children.

Such case occurs as much as 12 in translation news headline in this study. It means that from 20 samples taken randomly, $60 \%$ of data has changed and shifted in the focus of the problem. Thus it can be said that the translator wanted to highlight something more interesting to the target audience. Again, it can be said that the translator has much different ideology from the original author in conveying the message through translation.

\section{Addition and Omission}

Addition and omission as the last aspect discussed in this research were found in many cases. From the researcher' analysis, it is found that addition and omission done by the translation is about $70 \%$ from the 20 news headlines taken. Addition and omission are intended for a particular purpose since the addition and omission contained in more than a half of total news headlines taken as data. In this discussion, addition and omission will be discussed simultaneously in the analysis of case.

\section{ST: Setya Novanto Jalani Sidang Perdana jadi Sorotan Dunia \\ TT: Indonesia Politician`s Graft Trial Delayed by Stomach Woes}

This news headline is translated by both addition and omission. As seen in TT, the translator omits the name of the actor in TT. It is then changed into Indonesia Politician, the profession of the actor 'Setya Novanto'. The omission of the name in this case is intended by the translator so that the target text readers will be not confused about who Setya Novanto is meant to be. Only several people do know who Setya Novanto is. He is not as famous as Obama. Hence the translator changes it into Indonesia Politician in order that the people from outside Indonesia can notice the news easily. This indicates that the translator thinks about the target reader. The ideology of the translator has been affected by the culture in which the discourse will be appeared. 
The addition is the word delayed and the phrase 'Stomach Woes', which are not available in ST. This is meant by the translator to be balanced with the word delayed. If only the word delayed is added then the news headline is just ordinary. Therefore the translator also adds the phrase Stomach Woes to look unusual. This also indicates that the translator thinks about the effect to the readers and how to get the attention of the readers.

From the case discussed above, it is found that the ideology of original author in ST is different from the translator's ideology in TT. There are many differences in the choice of dominant lexical. The translator mostly uses the extreme, taboo and more surprising words in conveying the information. Seen syntactically, the translator changes the form from passive to active or vice versa in purpose. The translator wants to emphasize other effects to the readers in order to gain the attention. She also tried to impose her new ideas through a shift in focus themes. She makes new effects by adding and omitting and even generalizing the words to the translation. It is seen very obvious that this is very deliberately done to realize her ideas that the title of the news she translates should be able to have a surprising effect for the reader even though some of the translation results are inconsistent with the first discourse (ST).

Moreover, the analysis proves that ideology can be transmitted through translation. In this case, for the demand of her work, the translator has to translate in many considerations. Therefore, her ideology influences the way she make the discourse in target language (translated text). The competition in media has led many workers to think hard to survive from readers' choices. This is also what affects her translation of news headlines. She does not only try to adjust to the culture in which the discourse will be appear and be read, but she must also think about how the translated discourse can attract the attention of readers so that the site/company where she works get prestigious. Hence, it reflects the ideology of the translator. In sum, from analyzed data, it is enough to say that translation can be also used in delivering the ideology of someone. It also can be used as power to get something when it comes to the politics both in money and regime.

\section{CONCLUSION}

The goal of this study is to reveal the ideology of translator in translating news headlines by using CDA framework. The translator's ideology in translating news headlines is reflected by the text dimension proposed by Fairclough. From the analysis of text dimension in terms of lexical/diction, it was found that the translator has strong ideology and imposes it to the translated discourse. It can be seen from the dominant lexical choice. The translator usually used the extreme words which are eye-catching to the readers. In terms of grammatical form, the translator used active and passive form to emphasize something in order that the news headlines brought new effects to the readers in order to get the attention of the readers. The last aspect that translator used in conveying her ideology is by adding and omitting the information in news headline. This was intended by the translator to conform the target reader. Since the translator works in mass media (online), she had to find several ways to attract the readers in order that they are interested in a news just by looking at the headline.

\section{ACKNOWLEDGMENT}

I would like to thank to Indonesia Endowment Fund for Education (LPDP) Ministry of Finance Republik Indonesia for always giving supporting author by scholarship. I also thank to Yogyakarta State University (UNY) for giving me support to this research. Best regards for my family and also my lecture, Dr. Drs. Sulis Triyono, M. Pd who have given attention to this paper.

\section{REFERENCES}

[1] G. Farahani and V. Mehrdad, "The Role of Discourse Analysis in Translation,” Int. J. of Appl. Ling. \& Engl. Lit., vol. 2, no. 1, pp. 112 116, 2013.

[2] J. House, Translation Quality Assessment: Past and Present. New York: Routledge, 2015.

[3] S. S. Alghamdi, "Translation and Ideology: A Critical Discourse Analysis of Chomsky's "Media Control” and its Arabic Translation," Int. J. of Ling., vol. 6, no. 3, pp. 118-132, 2014.

[4] M. Aslani and B. Sahlani, "Ideology and Translation: A Critical Discourse Analysis Approach towards the Representation of Political News in Translation,” Int. J. of Appl. Ling. \& Engl. Lit., vol. 4, no. 3, pp. 80-88, 2015

[5] M. Mahdiyan, M. Rahbar, and S. M. Hosseini-Maasoum, “Applying Critical Discourse Analysis in Translation of Political Speeches and Interviews,” Acad. J. of Interdiscipl. Stud., vol. 2, no. 1, pp. 35-47, 2013.

[6] B. Al-Hejin, "Linking critical discourse analysis with translation studies: An example from BBC News,” J. of Lang. and Polit., vol. 11, no. 3, pp. 311-335, 2012.

[7] Z. Shahsavar and M. S. M. Naderi, "Investigating the Influence of Ideology on Translation: A Critical Discourse Analysis of 'A Tale of Two Cities' and its Persian Translations,” Int. J. of Engl. Lang. \& Transl. Stud., vol. 3, no. 1, pp. 35-48, 2015. 